\title{
Oncology Certified Nurse
}

National Cancer Institute

\section{Source}

National Cancer Institute. Oncology Certified Nurse. NCI Thesaurus. Code C71336.

A licensed Registered Nurse who has been working at least 1 year within the past 3 years, with at least 1,000 hours spent in Oncology Nursing within the past $21 / 2$ years and at least 10 continuing education hours in the field of Oncology Nursing completed over the past 3 years and who has passed the certification exam. 